\title{
In vitro Antifungal Activity of Extracts of Moringa oleifera on Phytopathogenic Fungi Affecting Carica papaya
}

\author{
Margaret Oniha*iD, Angela Eni(D), Olayemi Akinnola(i), Emmanuel Adedayo Omonigbehin, Eze Frank Ahuekwe (D), \\ John Folashade Olorunshola
}

Department of Biological Sciences, Covenant University, Ota, Ogun State, Nigeria

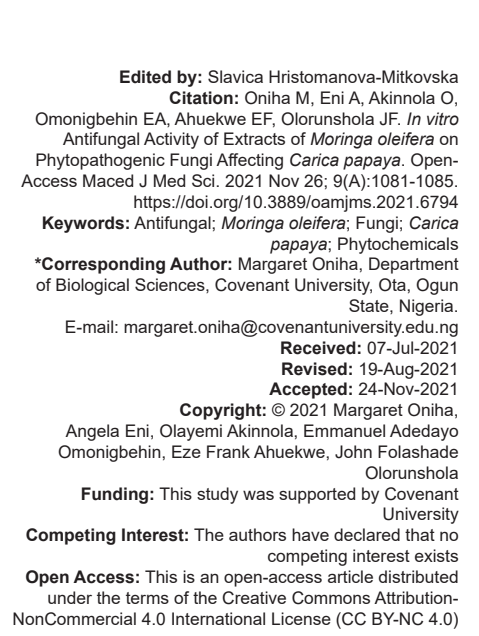

\section{Introduction}

The plant kingdom boasts of a broad diversity of integrant that is utilized in the treatment of diverse infections [1]. Flora serve as the wealthiest resource of drugs of conventional methods of healing, modern remedies, nutraceuticals, food augments, folk therapies, pharmaceutical intermediates, and synthetic units for simulated drugs [1]. Plants constitute the inexpensive and secure alternative etymologies of antimicrobials. Production of secondary metabolites by plants, which have been isolated and characterized, is utilized as effectual principles in medicinal preparation [2], [3]. Flavonoids, phenols and phenolic glycosides, unsaturated lactones, sulfur combinations, saponins, cyanogenic glycosides, benzophonones, xanthenes, anthraquinones, and glucosinolates are some of the common phytochemicals of plants [4]. Diverse studies have extensively shown that medicinal plants are regarded as wealthy etymologies of antimicrobial agents [5] with consequent screening for their prospective roles as alternative remedy in the remedy of infections by microorganisms [6] and reports boasts of diverse efficacious effects against both plant and human pathogenic microbes [7]. Reports have revealed the antifungal properties of many essential oils and extracts from plants, which possess no consequent effects on man and animals, hence the belief that diverse plant resources boast of antifungal activity [8]. In plants, the prominent disease-causing agents are fungi that cause alterations both on field and at post-harvest [9]. Research has revealed the quality problems in fruits and vegetables caused by a broad range of diverse fungal species that include features, nutritional benefits, organoleptic traits, and limited shelf life with some cases of allergic or toxic disorders among consumers caused indirectly by fungi from the production of allergens or mycotoxins [9], [10], [11]. Basically, synthetic fungicides are employed to control pest and fungal diseases but with increased restriction in application due to negative impacts on human health and environs [11]. Moringa oleifera Lam, a broadly grown strains of Moringaceae family, is popularly referred to as a "Miracle tree," with virtually all of its parts possessing useful products for humankind. The plant Moringa is indigenous to the sub-Himalaya tract of India, Pakistan, Bangladesh, and Afghanistan [12]. Aisha et al. [12] stated that in 
indigenous medicine, almost all the segments of this plant including the root, bark, gum, foliage, fruits, florets, ovules, and ovule oil have been utilized for the remedy of differential sicknesses. In furtherance, it has been opted for as an excellent aboriginal etymology of highly palatable protein, calcium ( $\mathrm{Ca})$, iron ( $\mathrm{Fe})$, Vitamin $\mathrm{C}$, and carotenoids acceptable for implementation in numerous economically growing regions where undernourishment is of vital concern [12]. Reports from Aisha et al. [12] and Dillard and German [13] and revealed that the plant presents abundant etymology of B-carotene, protein and Vitamin C, calcium, and potassium and serves as a good genesis of natural antioxidants, thereby increasing the shelf-life of fat containing foods as a result of the presence of different types of antioxidants compounds that include ascorbic acid, flavonoids, phenolics, and carotenoid. Ethnobotanically, the plant has been reported in the remedy of ascites, rheumatism, and venomous bites and as cardiac and circulatory restorative [7]. Reports of its hepatoprotective [14] and anti-malignancy [15] roles have been documented. Ovules of $M$. oleifera have been utilized for the effective remedy of athlete's foot and tinea [16].

Studies abound on the antimicrobial activities of diverse plant part extracts of $M$. oleifera but there is a need to continuously conduct updates on its efficacy on evolving phytopathogenic fungi, especially the emerging resistant strains. This study was aimed at identifying the phytochemical components present in the differential leaf extracts of $M$. oleifera and to determine the antifungal activity of $M$. oleifera leaf extracts employing in vitro antifungal screening techniques.

\section{Materials and Methods}

\section{Plant collection and identification}

Leaves of $M$. oleifera were obtained from the Covenant University Farm in Ota, Ogun State, Nigeria. Authentication of the already identified plant species (voucher specimen number: Mo/Bio/H816) was conducted at the Herbarium Section of the Forestry Research Institute of Nigeria, Ibadan, Nigeria, and allocated forestry herbarium identification number of M. oleifera-FHI No: 110313.

\section{extracts}

\section{Preparation of aqueous and organic}

Mature disease-free leaves were rinsed to eliminate dust and other foreign particles, air-dried in a shaded area at room temperature for a period of 3 weeks [17]. Dried materials were grounded into powder employing a blender and stored in airtight bottles at room temperature $\left(25-30^{\circ} \mathrm{C}\right)$ until use. Weighed amount of
$300 \mathrm{~g}$ of the dried powder leaf was extracted by soaking and macerating in $1.5 \mathrm{~L}$ of $\mathrm{n}$-hexane, ethyl acetate, ethanol, methanol, and water at ambient temperature for $72 \mathrm{~h}$ for each solvent used. Mixtures were vigorously agitated and subsequently filtered through cheese cloth and Whatman No.1 filter paper. Resultant filtrates were subsequently concentrated using a rotary evaporator and the solvents used were recovered under pressure until slurried/dry extracts were achieved. The five different crude extracts obtained were then kept at $4^{\circ} \mathrm{C}$ for subsequent use. Concentrated extracts were later dissolved in appropriate volumes of dimethyl sulfoxide (DMSO) to make the various concentrations for antifungal screening. All the stock solutions were stored in sterile capped bottles, labeled accordingly, and stored at $4^{\circ} \mathrm{C}$ for analysis. Each antifungal test was carried out in three replicates against each fungal isolate.

\section{extracts \\ Phytochemical screening of plants}

Assessments were carried out on the crude extracts of the five crude extracts to detect the presence of phytochemicals according to protocols previously described by Sofowora [18] and Trease and Evans[19].

\section{Fungal isolates and inoculum quantification}

Fungi were obtained from pawpaw samples from the Pawpaw research demonstration farm, Covenant University, Ota. Aspergillus niger, Aspergillus fumigatus, Aspergillus flavus, Rhizopus spp., Penicillium spp., and Trichoderma spp. were identified, maintained, and later stored in cryovials at $-20^{\circ} \mathrm{C}$ at the Microbiology Laboratory, Covenant University, Ota. Fresh fungal isolates of $72 \mathrm{~h}$ were prepared on PDA by subculturing and fungal spore suspensions were obtained after filtration. Spore suspension for the different fungal isolates was evaluated using hemocytometer cell counting chamber and final inoculum was adjusted to obtain 0.5 McFarland's standard $\left(10^{6}\right.$ spores $\left./ \mathrm{ml}\right)$.

\section{M. oleifera \\ Antifungal activity of crude extracts of}

Potato dextrose agar medium (Oxoid) was made ready following the manufacturer's instructions. Antifungal activity of the crude extract was carried out using the agar well-diffusion technique as described by Vollekova et al. [20]. Standard dose was constituted by dissolving $1000 \mathrm{mg}$ of crude extract in $1 \mathrm{ml}$ of DMSO (1:1) for all the extracts. The antifungal agent ketoconazole $(100 \mathrm{mg} / \mathrm{ml})$ was utilized as the positive control while DMSO was used as the negative control. Surface of medium was streaked with the standardized fungal spore suspension for uniform distribution of the inoculum on the agar. The seeded 
plates were let to dry. Wells were then bored into agar media utilizing a sterile cork borer of $10 \mathrm{~mm}$ and these wells were thus filled with $0.2 \mathrm{ml}$ of the various extract concentrations. Sequel to the diffusion of the extracts into the agar at ambient temperature, the bored agar plates were incubated at room temperature for 3-5 days and observations made at 24-72 h. Antifungal activity of the leaf extracts was determined by measuring zone of inhibition surrounding the agar wells. The sensitivity tests were conducted in triplicates and the average diameter of the zones of inhibition was recorded accordingly.

\section{Determination of minimum inhibitory concentration (MIC) and minimum fungicidal concentration (MFC) of plant extracts}

The MIC and MFC of the plant extracts were evaluated using agar well diffusion as described by Samie and Mashau [21] and agar dilution method by Sule et al. [4]. Different concentrations of the extracts were constituted $(125 \mathrm{mg} / \mathrm{ml}, 62.5 \mathrm{mg} / \mathrm{ml}, 31.25 \mathrm{mg} / \mathrm{ml}$, and $15.625 \mathrm{mg} / \mathrm{ml}$ ) from which the MIC and MFC of the plant extracts were determined. Potato dextrose agar was made ready according to the manufacturer's instructions and apportioned into Petri plates. Agar surfaces were seeded with $0.1 \mathrm{ml}$ of standardized fungal spores and let to dry. Sterile $10 \mathrm{~mm}$ diameter cork borer was used to punch two equidistant holes in the middle of the inoculated agar plates. These holes were then supplied with $0.2 \mathrm{ml}$ of the various extract concentrations. After the diffusion of the extracts into the agar at room temperature, the bored agar plates were incubated at ambient temperature for 3-5 days and observations made at 24-72 h. The antifungal activity of the leaf extracts was determined by measuring zone of inhibition surrounding the agar well. Negative and positive control plates were without any plant extracts but ketoconazole (positive control) and DMSO (negative control) were added, respectively. The sensitivity tests were conducted in triplicates and the mean diameter of the zones of inhibition was recorded accordingly.

\section{Data analysis}

The diameters of zones of inhibition for the in vitro antifungal activity were expressed as means of three replicates. Significant differences between and within the averages of treatments and controls were analyzed using ANOVA at $\mathrm{p} \leq 0.05$ and post hoc tests. Statistical analyses were computed using SPSS version 20 software package.

\section{Results and Discussion}

The alternative control methods for plant diseases are required due to biohazards, pollution, resistance to fungicides by the fungal pathogens, and high cost of producing novel chemicals. Studies have been orchestrated on the employment of plant procured products as disease control agents because of their minimal toxicity to mammals, environmentally friendly roles, and broad public acceptance [22]. Abundant aromatic and medicinal plants are bestowed with phytochemical components that include polyphenols, flavonoids, saponins, alkaloids, and others in their different parts (leaves, bark, flowers, seeds, wood, and branches) which possess extensive applications as antioxidants and antimicrobials and are acknowledged for their pharmaceutical and biopesticide potentials [23]. This medicinal plant was selected based on it ethnobotanical and pharmacological usage as well as antimicrobial properties [12], [22], [24]. The phytochemical screening of the different plant extracts showed saponins, tannins, anthocyanin and betacyanin, cardiac glycosides, phenols, carbohydrates, coumarins, and terpenoids and triterpenoids in all the leaf extracts as presented in Table 1. This finding agreed with the reports of earlier researchers [12], [24] who found alkaloids, saponins, tannins, anthocyanin and betacyanin, cardiac glycosides, phenols, carbohydrates, coumarins, and terpenoids. The results obtained portrayed that the five crude leaf extract types (n-hexane, ethyl acetate, ethanol, methanol, and aqueous) at $1000 \mathrm{mg} / \mathrm{ml}$ concentration of $M$. oleifera evaluated had antifungal activity against all the fungal genera tested, as shown in Figure 1. The highest antifungal activity was seen in M. oleifera against Penicillium spp. with a $33 \mathrm{~mm}$ zone of inhibition while the least zone of inhibition was seen in the n-hexane extract against $A$. flavus $(20 \mathrm{~mm})$. For the antifungal activity of control antifungal agents, the zones of inhibition measured between $11-13 \mathrm{~mm}$ and $0 \mathrm{~mm}$ for the positive and negative controls, respectively.

Paray et al. (2018) carried out a study on the petroleum ether extracts of folioles and stem bark of $M$. oleifera against the growth of $A$. niger, Sclerotium rolfsii, Botryodiplodia theobromae, and Penicillium oxalicum with extracts of both plant parts showing inhibitory activity. In furtherance, the study observed that the leaf extract showed more significant inhibitory action compared to the bark extract. Research by Aisha

Table 1: Results for phytochemical screening of $n$-Hexane, ethyl acetate, ethanol, methanol, and aqueous extracts of Moringa oleifera

\begin{tabular}{|c|c|c|c|c|c|}
\hline Tests & n-Hexane & Ethyl acetate & Ethanol & Methanol & Water \\
\hline Alkaloids & - & - & + & - & - \\
\hline Quinones & - & - & - & - & + \\
\hline Glycosides & - & - & - & - & - \\
\hline Flavonoids & - & - & - & - & - \\
\hline Saponins & + & - & - & - & + \\
\hline Tannins & - & - & + & - & + \\
\hline Carbohydrates & - & - & - & - & + \\
\hline Anthocyanin and betacyanin & - & - & - & + & ++ \\
\hline Cardiac glycosides & - & + & + & + & + \\
\hline Terpenoids & - & + & - & + & - \\
\hline Triterpenoids & - & - & + & + & - \\
\hline Phenols & - & - & - & + & - \\
\hline Coumarins & - & + & - & + & + \\
\hline Steroids & - & - & - & - & - \\
\hline Acid & - & - & - & - & - \\
\hline
\end{tabular}




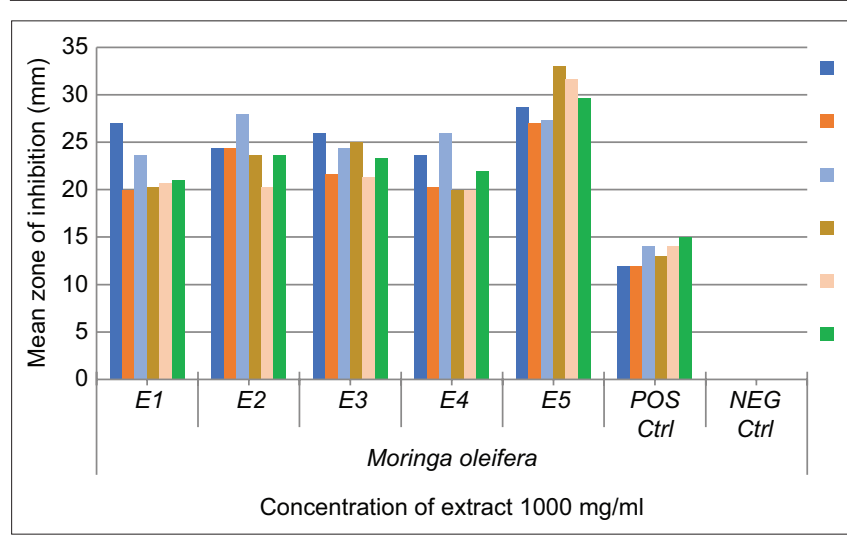

Figure 1: Mean zones of inhibition for antifungal activity of Moringa oleifera against fungal isolates from pawpaw (Carica papaya) samples. E1-n-hexane, E2-ethyl acetate, E3-ethanol, E4-methanol, E5-aqueous, POS Ctrl-Ketoconazole and NEG CtrI-DMSO

et al. [12] revealed that the ethanolic extract had high inhibitory activity against $A$. niger, Rhizopus stolonifer, and Candida albicans at varying concentrations with C. albicans being the most sensitive and closely followed by the afore-mentioned fungi. A significant difference at $p \leq 0.05$ for all the extracts tested against A. niger, A. flavus, Rhizopus oryzae, Penicillium sp., Trichoderma sp., and $A$. fumigatus using a two-way ANOVA with treatment (test extracts and control) as the predictor and fungal growth as the response variable followed by post hoc tests for comparison. Results also show that the aqueous extract of $M$. oleifera was most significant $(p<0.05)$. In addition, significant difference was observed across all the extract types $(p=0.000)$ as compared to the controls, but no significant difference was observed for the isolates $(p>0.05)$. The results for MIC and MFC were established for the leaf extracts of the plant. MIC values for the extract types were $15.625 \mathrm{mg} / \mathrm{ml}$ while the MFC values ranged from 31.25 to $62.5 \mathrm{mg} / \mathrm{ml}$.

\section{Conclusion}

Medicinal plants still subsist as the best resource for provision of diverse drugs and pesticides. $M$. oleifera leaf extracts have significant antifungal activity against common fungal isolates cultured from samples of Carica papaya. This shows that its extracts can serve as an alternative and ecofriendly means of controlling and treating fungal diseases in plants.

\section{References}

1. Paray AR, Bhakat M, Mohanty TK, Behare P, Lone SA, Parry UR, et al. Antimicrobial activity of crude aqueous extracts of Moringa oleifera, Azadirachta indica, Carica papaya, Tinospora cordifolia and Curcuma longa against certain bacterial pathogens. J Pharmacogn Phytochem 2018;7:984-94.

2. Taylor JL, Rabe J, Megaw LJ, Jafer AK, Van Staden J. Towards the scientific validation of traditional medicinal plant. Plant Growth Regular 2001;34:23-37.

3. Nube NS, Afolayon AJ, Okoli AL. Assessment techniques of antimicrobial properties of natural compounds of plant origin: Current methods and future trends. Afr J Biotechnol 2008;7:1797-806.

4. Sule WF, Okonko IO, Omo-Ogun S, Nwanze JC, Ojezele MO, Ojezele OJ, et al. Phytochemical properties and in-vitro antifungal activity of Senna alata Linn. Crude stem bark extract. J Med Plants Res. 2011;5(2):176-83.

5. Mahesh B, Satish S. Antimicrobial activity of some important medicinal plant against plant and human pathogens. World $\mathrm{J}$ Agric Sci. 2008;4:839-43.

6. Abdallah ME, Ali HB, Mohamed AE, Mohamed E, Mohamed AA. In vitro antifungal activity of some plant essential oils. Int $\mathrm{J}$ Pharmacol 2015;11:56-61.

7. Shindano J, Kasase C. Moringa (Moringa oleifera): A source of food and nutrition, medicine and industrial products. ACS Symp Ser. 2009;1021:421-67.

8. Negri M, Salci TP, Shinobu-Mesquita CS, Capoci IR, Svidzinski TI, Kioshima ES. Early state research on antifungal natural products. Molecules. 2014;19:2925-56. http://doi. org/10.3390/molecules 19032925

PMid:24609016

9. Dellavalle PD, Cabrera A, Alem D, Larrañaga P, Ferreira F, Dalla Rizza M. Antifungal activity of medicinal plant extracts against phytopathogenic fungus Alternaria spp. Chilean J Agric Res. 2011;71(2):231-9.

10. Agrios GN. Losses caused by plant diseases. In: Plant Pathology. Oxford, United Kingdom: Elsevier; 2004. p. 29-45.

11. Joshi $S$, Kumar P, Pant P, Sati SC. A comparative evaluation of Kumaun Himalayan gymnosperms for their antifungal potential against plant pathogenic fungi. J Phytopharmacol. 2018;7(3):230-41.

12. Aisha SB, Kutama AS, Kabir S, Paul AT. Phytochemical screening and antifungal activity of Moringa oleifera on some selected fungi in Dutse, Jigawa State. Global Adv Res J Agric Sci. 2016;5(6):243-8.

13. Dillard CJ, German JB. Phytochemical; nutraceutical, and human health. A review. J Sci Food Agric. 2000;80:1744-56.

14. Pari L, Kumar NA. Hepatoprotective activity of Moringa oleifera on antitubercular drug-induced liver damage in rats. J Med Food. 2002;5(3):171-7. http://doi.org/10.1089/10966200260398206 PMid:12495589

15. Murakami A, Kitazono Y, Jiwajinda S, Koshimizu K, Ohigashi H Niaziminin, a thiocarbamate from the leaves of Moringa oleifera, holds a strict structural requirement for inhibition of tumorpromoter-induced Epstein-Barr virus activation. Planta Med. 1998;64:319-23. http://doi.org/10.1055/s-2006-957442 PMid:9619112

16. Chuang PH, Lee CW, Chou JY, Murugan M, Shieh BJ, Chen HM Antifungal activity of crude extracts and essential oil of Moringa oleifera Lam. Bioresour Technol. 2007;98:232-6. http://doi. org/10.1016/j.biortech.2005.11.003 PMid: 16406607

17. Vinoth B, Manivasagaperumal R, Rajaravindran M. Phytochemi cal analysis and antibacterial activity of Azadirachta indica Juss. Int J Res Plant Sci. 2012;2(3):50-5.

18. Sofowora A. Medicinal plants and traditional medicinal in Africa. In: Screening Plants for Bioactive Agents. $2^{\text {nd }}$ ed. Ibadan, Nigeria: Spectrum Books Ltd., Sunshine House; 1993. p. 134-56. 
19. Trease GE, Evans WC. Pharmacognosy: A Physician Guide to Herbal Medicine London. $13^{\text {th }}$ ed. Tindall, London: ELBS/ Bailliere; 1989. p. 176-80.

20. Vollekova A, Kostalova D, Sochorova R. Isoquinoline alkaloids from Mahonia aquiliform stem bark is active against Mallasssezia sp. Foliar Microbiol. 2001;46(2):107- http://doi. org/11.10.1007/BF02873586

PMid:11501395

21. Samie A, Mashau F. Antifungal activities of fifteen Southern African medicinal plants against five Fusarium species. J Med Plants Res. 2013;7(25):1839-48.
22. Riad SR, Abdallah AM. Antifungal activity of Moringa oleifera oil and seed extract against some plant pathogenic fungi. Middle East J Agric Res. 2014;3(2):242-9.

23. Al-Huqail AA, Said I, Behiry SI, Mohamed ZM, Salem MZ, Ali $\mathrm{HM}$, et al. Antifungal, antibacterial, and antioxidant activities of Acacia saligna (Labill.) H. L. Wendl. Flower extract: HPLC analysis of phenolic and flavonoid compounds. Molecules. 2019;24(700):1-14. http://doi.org/10.3390/molecules24040700 PMid:30781352

24. Nweke FU. Antifungal activity of petroluem ether extracts of Moringa oleifera leaves and stem bark against some plant pathogenic fungi. J Nat Sci Res. 2015;5(8):1-6. 